\title{
"Manna from heaven": The effect of noncontingent appetitive reinforcers on learning in rats
}

\author{
WILLIAM F. OAKES, JAN L. ROSENBLUM, and PAUL E. FOX \\ Brooklyn College, City University of New York, Brooklyn, New York 11210
}

\begin{abstract}
Three groups of rats received food pellets in the first phase of the experiment. Members of the contingent group received the pellets contingent upon their nose-poke responses. Subjects in the noncontingent group, yoked to members of the contingent group, received pellets whenever their yoked contingent animal nose-poked, but independent of the noncontingent animal's behavior. Members of the control group received the same numbers of pellets in their home cages $50 \mathrm{~min}$ later. In the second phase, the three groups learned a leverpress response with food reinforcement. Two of the three dependent measures showed a detrimental effect of the first-phase experience on leverpressing performance for the noncontingent group, compared with the contingent and control groups, which did not differ from each other. It was concluded that an appetitive learned helplessness effect has been demonstrated.
\end{abstract}

"Response-outcome independence is an active form of learning, and like any other active form of learning, it can proactively interfere with contravening forms of learning" (Maier \& Seligman, 1976, p. 18). The basis for the learned helplessness phenomenon suggested in the above quotation implies that later learning should be retarded or impaired by the experience of either appetitive or aversive events uncorrelated with the organism's behavior. The virtual plethora of animal studies demonstrating the aversive case has not, however, been matched in the appetitive case. Seligman, Meyer, and Testa (cited by Seligman, 1975, p. 34) gave groups of rats different amounts of free food pellets dropped through the tops of operant chambers. Those receiving the most free food then experienced the greatest difficulty in learning to barpress for food reinforcement. In that study, however, the variables of the amount of free food received and the experience of response-reinforcer independence were confounded. Also, unfortunately, Seligman provided very few details of that experiment.

Engberg, Hansen, Welker, and Thomas (1973) used two groups of pigeons. One learned to press a treadle to receive food, and the other received responseindependent food on a variable-time (VT) schedule. The latter group was then found to be retarded in comparison with the treadle group in later autoshaping of keypecking. In another study, Welker (1976) trained one group of pigeons to peck a key for food, and a second group, yoked to the first, received the same amount of food on a response-independent basis. A third group received only hopper training. The response-independent group was then found to be retarded in later learning of a treadlepress response for food in comparison with the other two groups.

Palese (1977) used three groups of rats, with one group receiving food pellets delivered to the food hopper contingent upon their performing a nose-poke response. A second group, yoked to the first, received response-independent pellets dropped through a hole in the top of the chamber whenever the yoked animal from the first group nose-poked. The third group, also yoked to the first, received response-independent pellets delivered to the food hopper whenever the yoked animal in the first group nose-poked. That training continued for 9 days, following which, the animals were given leverpress training in a different apparatus in a different room. In the leverpress training, a retractable lever was extended into an operant chamber. If the animal pressed the lever, it was immediately retracted and a food pellet was delivered into the hopper. If the animal did not press the lever, it remained extended for $10 \mathrm{sec}$ and then was retracted, with the animal receiving no food pellet. Extension of the lever was on a VT 45 -sec schedule. The results showed that, with respect to the number of trials (lever extensions) on which the animal pressed the lever and the speed to press the lever (1/latency in seconds), the response-dependent (nose-poke) group performed significantly better than either of the two response-independent groups, which did not differ from each other. Palese concluded that the response-independent delivery of the food pellets in the first phase had retarded the later learning of the leverpress response. It is possible to interpret those results on the basis of positive transfer from the nose-poke response to the leverpress response, however. A similar interpretation, on the basis of positive transfer from the treadlepress response to the keypeck response is also possible in the Engberg et al. (1973) study mentioned above.

Beatty and Maki (1979) reported failure to observe 
"learned laziness" in rats. In that study, the animals first received free pellets on a VT 60 -sec schedule for $0,1,10$, or 2050 -min sessions. Food was delivered only after $10 \mathrm{sec}$ in which a leverpress had not occurred. This was followed by a test day, on which food pellets were contingent on leverpressing, after the lever was first baited with one pellet. The results showed that the prior experience with the noncontingent delivery facilitated rather than retarded the learning of the leverpress response. The animals with 20 days of such noncontingent experience learned the leverpress best. In a second experiment, those investigators had one group of animals who received one $60-\mathrm{min}$ session of noncontingent food on a VT $60-\mathrm{sec}$ schedule. A second group received 30 such 60 -min sessions. A third group lived $24 \mathrm{~h} /$ day in a similar operant chamber, receiving noncontingent pellets on a VT 6-min schedule for 15 days. The test was then similar to that in the first experiment. Again, no retardation of subsequent learning was observed as a result of the noncontingent experience. Neither the 30-day group nor the "live-in" group differed from the 1-day group.

Wheatley, Welker, and Miles (1977) had reported that deficits in instrumental responding for food were observed in rats given prior experience with noncontingent food. However, they subsequently reported (Wheatley, Welker, \& Miles, 1978) that there had been errors in the statistical analysis and that the differences between the noncontingent and control groups actually were not significant.

The evidence in the literature for the appetitive analogue of the learned helplessness effect may thus be seen as not too strong. The present study was designed to be an essential replication of the Palese (1977) study, which was somewhat similar to the Seligman et al. (cited in Seligman, 1975) study, both of which produced results suggestive of a helplessness effect, but both of which permitted alternative interpretations. Animals in the present study all received the same amount of time in the apparatus and the contingent and noncontingent groups received the same number of pellets in the first phase of the experiment, so those variables were not confounded with the contingency/ noncontingency variable in the present study, as in the Seligman et al. study. Instead of the group receiving noncontingent pellets in the food hopper that Palese (1977) used, the present study utilized a control group receiving no pellets in the apparatus during the first phase. This group thus provides a baseline in the second phase to permit a determination of whether any difference in leverpress learning of the contingent nose-poke group and the noncontingent group is due to a facilitation of the learning of the former or a retardation of the learning of the latter by their first-phase experience. We thus used three groups, differing on the basis of their experience during the first phase. The contingent group received food pellets contingent on nose pokes, the noncontingent group were yoked with the contingent animals and received food pellets on a noncontingent basis. The control group spent the same amount of time in the first-phase apparatus and received no food there, but they received the same number of pellets as their yoked contingent and noncontingent cohorts after they returned to their living cages. All groups then learned a leverpress response in the second (test) phase of the experiment.

\section{METHOD}

\section{Subjects}

The subjects were 21 female Sprague-Dawley albino rats weighing $300-350 \mathrm{~g}$ at the beginning of the experiment. They were given access to lab chow for $1 \mathrm{~h} /$ day throughout the experiment, with water always available in the living cages.

\section{Apparatus}

The apparatus and procedure were the same as those of Palese (1977), with a no-food control group substituted for the "hopper" noncontingent group that Palese used.

Materials used included six experimental rat chambers, three insulating chests, three retractable levers, and three nose-poke devices. Three of the experimental chambers with nose-poke devices were used in the first phase; in a different room, the other three chambers with the retractable levers and the insulating chests were used in the second (test) phase.

\section{First Phase}

The three chambers measured $30 \times 30 \times 30 \mathrm{~cm}$. Each contained a food hopper and a nose-poke device consisting of a $5-\mathrm{cm}$-square tube with an interruptable infrared light beam located $1 \mathrm{~cm}$ down the length of the tube. The nose-poke devices and food hoppers were located $17.5 \mathrm{~cm}$ apart, and each was $3 \mathrm{~cm}$ from the floor and $3.5 \mathrm{~cm}$ from the side walls. The nose-poke devices were near the left side wall, and the food hoppers were located near the right side wall. The intelligence panels and the walls opposite to them were painted flat black. The remaining two sides were painted gloss white. All floors were made of brown wood-grain Formica, and the tops were clear Plexiglas. Illumination of the first-phase environments was by fluorescent tubes in the ceiling of the experimental room.

\section{Second Phase}

The three testing chambers in their insulating chests were located in an experimental room different from that used in the first phase. Each chamber was $30 \times 24 \times 24 \mathrm{~cm}$ and contained a retractable lever and a food hopper. The levers were $2.8 \mathrm{~cm}$ wide and $1 \mathrm{~cm}$ thick and protruded $2 \mathrm{~cm}$ into the chambers when fully extended. The levers were located $7.5 \mathrm{~cm}$ from the floor and $3 \mathrm{~cm}$ from the right side walls. The food hoppers were located at the center of the intelligence panels, $1.5 \mathrm{~cm}$ from the floors. The intelligence panels and their opposite walls were made of steel-gray aluminum. The side walls and ceilings were made of clear Plexiglas, and the floors were steel rods spaced $2 \mathrm{~cm}$ apart. Illumination was by a 7.5-W bulb hung from the center of the ceiling of the insulating chest. The first- and second-phase environments for the animals were thus quite different.

\section{Procedure}

Rats were assigned to the three groups: contingent, noncontingent, and control. Each rat was given an adaptation day in the apparatus before the first phase began, being placed into a first-phase chamber for $50 \mathrm{~min}$ with no food available and with no programmed effect of responses. On each of the following 9 days, constituting the first phase, a trio of three animals, one each from the contingent, noncontingent, and 
control groups, occupied the three chambers for a session lasting a maximum of $50 \mathrm{~min} /$ day. Seven trios were thus run each day.

On the 1st day of Phase 1, food reinforcement (45-mg Noyes pellets) was delivered to the food hopper of a subject from the contingent group contingent upon its performance of a nose-poke response, defined as an excursion of the head of the animal a sufficient distance into the nose-poke tube to interrupt the infrared light beam located $1 \mathrm{~cm}$ down the tube. Or, if the contingent animal did not nose-poke, a pellet was delivered on a VT 45-sec schedule. During the subsequent 8 days of Phase 1, food was presented to the animals contingent only on the occurrence of nose-poke responses. Electromechanical equipment was used to record the responses and to deliver reinforcements.

An animal from the noncontingent group received free food pellets at the same times (i.e., yoked) as the contingent animal while occupying an identical chamber in the same room. Nosepoking had no programmed consequences for the noncontingent subjects. The free pellets for the noncontingent animals were dropped through a hole centrally located in the ceiling of the chamber.

Subjects in the control group occupied the third identical chamber in the first-phase room but did not receive any food pellets during a session. Nose-poking had no programmed consequences for the control subjects.

The above procedures continued until the animals in the contingent group had completed 100 responses and/or $50 \mathrm{~min}$ had passed on each of the 9 days of the first phase. The control animals were given, in their home cages $50 \mathrm{~min}$ after the completion of their sessions, the number of pellets received by the contingent and noncontingent animals in each of their trios. The three members of each trio then received their $1 \mathrm{~h}$ free access to lab chow after the control animal had finished eating the Noyes pellets that had been given to it in a little cup. In this way, all three groups were equated for the amount of time spent in the Phase 1 apparatus and for the number of Noyes pellets received during Phase 1 .

Phase 2, involving two daily sessions consisting of 80 testing trials in a second experimental room, began on the day following the Phase 1 procedures described above. On each day, the animals were placed into the Phase 2 testing chamber and given 80 presentations of the lever extended into the chamber. On each trial, the lever was extended into the chamber for a maximum of $10 \mathrm{sec}$ and then retracted if it was not pressed during that period. The presentations of the lever were on a VT 40-sec schedule. If the animal pressed the lever during the 10-sec interval after it was fully extended, the lever was immediately retracted and a food pellet was delivered to the hopper. If the lever was not pressed, it was retracted at the end of the 10-sec trial period and no food was presented. Dependent measures recorded were the latency on each trial, the number of trials with a leverpress, and the number of trials before the first leverpress.

\section{RESULTS}

Analysis of variance was made of each of the three dependent measures for Test Day 1, for Test Day 2, and for Test Days 1 and 2 combined. Planned comparisons were also made, testing for a helplessness effect, $\left(m u_{\text {contingent }}+m u_{\text {control }}\right) / 2=m u_{\text {contingent }}$, and for a facilitation effect of the contingent experience, $\mathrm{mu}_{\text {contingent }}=\mathrm{mu}_{\text {control. }}$. The latencies were transformed to speed measures by taking the reciprocal of the latencies in seconds, and the analyses were made on the speed values. None of the differences was significant for the speed measure (all Fs $<1$ ).
The other two measures did indicate a significant helplessness effect, but no facilitation effect of the contingent experience. The analysis of the frequency of leverpress data showed that the groups differed marginally overall on Day $1[\mathrm{~F}(2,18)=3.21, .1>\mathrm{p}>.05]$ and significantly on Day $2[\mathrm{~F}(2,18)=4.63, \mathrm{p}<.05]$ and on Days 1 and 2 combined $[F(2,18)=4.99, p<.05]$. For frequency of leverpress, the planned comparison for helplessness $\left[\left(\mathrm{mu}_{\text {con tingent }}+m u_{\text {control }}\right) / 2=m u_{\text {non }}\right.$ contingent] was significant for Day $1[F(1,18)=4.85$, $\mathrm{p}<.05]$, for Day $2[\mathrm{~F}(1,18)=8.35, \mathrm{p}<.01]$, and for Days 1 and 2 combined $[\mathrm{F}(1,18)=8.49, \mathrm{p}<.01]$. The planned comparison for facilitation [ $\mathrm{mu}_{\text {contingent }}$ $\left.=\mathrm{mu}_{\text {control }}\right]$ was nonsignificant for Day $1[\mathrm{~F}(1,18)=$ $1.57, \mathrm{p}>.05]$, Day $2[\mathrm{~F}(1,18)=1.57, \mathrm{p}>.05]$, and for Days 1 and 2 combined $[F(1,18)=1.50, p>05]$.

The analysis of variance of the number of trials before a leverpress showed that the groups differed significantly overall on Day $2[\mathrm{~F}(2,18)=4.13, \mathrm{p}<.05]$. The planned comparison for helplessness was significant only on Day 2 as well $[F(1,18)=8.26, p<.01]$. The planned comparisons for a facilitation effect were uniformly nonsignificant [Day $1, F(1,18)=1.66$; Day 2 , $\mathrm{F}(1,18)<1$; Days 1 and 2 combined, $\mathrm{F}(1,18)<1$ ]

A significant detrimental effect of the first-phase experience was thus shown by the frequency data for the noncontingent group compared with the contingent and control groups on Test Day 1, Test Day 2, and on both test days combined, but the contingent and control groups did not differ from each other in any of those comparisons. The trials-to-the-first-press data showed a significant detrimental effect for the noncontingent group compared with the contingent and control groups only on Test Day 2. Again, the contingent and control groups did not differ significantly from each other.

\section{DISCUSSION}

Two of the three dependent measures indicated that the experience of the animals in the noncontingent group in receiving pellets of food dropped through the ceiling of the chamber in Phase 1 at intervals unrelated to their behavior had an adverse effect on their later learning to leverpress for food pellets. The noncontingent animals pressed the lever with less frequency than the contingent and control group animals on both test days.

The noncontingent animals had more extensions of the lever before they pressed it on the 2 nd day. It is surprising that the same was not true on the 1st test day. Examination of the data shows, however, that some of the concontingent animals pressed the lever early on Test Day 1 but then stopped pressing the lever for the duration of the experiment. It is interesting that this is consistent with findings in the early learned helplessness research with dogs exposed to inescapable shock (Overmier \& Seligman, 1967; Seligman \& Maier, 1967). Dogs in those studies not only refrained from performing escape responses in the subsequent shuttlebox escape/avoidance task but also failed to follow an occasional successful barrier jump with another. The explanation suggested by those investigators involved a cognitive deficit; that is, the helpless animals did not perceive the relationship between their behavior and the termination of the shock.

Some explanation along those lines would be consistent with our findings. Our noncontingent animals had difficulty in subsequently learning that there was a relationship between their 
behavior (leverpressing) and the delivery of the pellets in the operant chamber after experiencing the noncontingent delivery of food in Phase 1. Mackintosh (1973) has suggested that animals "learn to ignore" stimuli that are experienced as nonpredictive of the occurrence of a reinforcer. Perhaps our animals "learned to ignore" their own responses as predictors of the occurrence of food reinforcement as a result of their experiencing their behavior as uncorrelated with the appearance of the "manna from heaven." That learning would then have to be overcome when, subsequently, the occurrence of reinforcement is made dependent upon the animal's behavior.

We have no explanation to suggest for why Beatty and Maki (1979) and Wheatley et al. $(1977,1978)$ did not obtain an appetitive helplessness effect. We conclude, however, that such an effect is obtainable in rats with a "manna from heaven" procedure such as that used in the present experiment.

\section{REFERENCES}

Beatty, W. W., \& MaKi, W. S. Acquisition of instrumental responding following noncontingent reinforcement: Failure to observe "learned laziness" in rats. Bulletin of the Psychonomic Society, 1979, 13, 268-271.

Engberg, L. A., Hansen, G., Welker, R. L., \& Thomas, D. R. Acquisition of key-pecking via authoshaping as a function of prior experience: “Learned laziness"'? Science, 1973, 181, 367368.

Mackintosh, N. J. Stimulus selection: Learning to ignore stimuli that predict no change in reinforcement. In R. A. Hinde \& J. Stevenson-Hinde (Eds.), Constraints on learning. New York: Academic Press, 1973.

Maier, S. F., \& Seligman, M. E. P. Learned helplessness: Theory and evidence. Journal of Experimental Psychology: General, 1976, 105, 3-46.

Overmier, J. B., \& Seligman, M. E. P. Effects of inescapable shock upon subsequent escape and avoidance learning. Journal of Comparative and Physiological Psychology, 1967, 63, 28-33.

Palese, R. P. Acquisition of a discrete-trial operant appetitive response in rats after exposure to response-independent food. Unpublished doctoral dissertation, City University of New York, 1977.

Seligman, M. E. P. Helplessness. San Francisco: Freeman, 1975.

Seligman, M. E. P., \& Maier, S. F. Failure to escape traumatic shock. Journal of Experimental Psychology, 1967, 74, 1-9.

Welke r, R. L. Acquisition of a free-operant-appetitive response in pigeons as a function of prior experience with responseindependent food. Learning and Motivation, 1976, 7, 394-405.

Wheatley, K. L., Welker, R. L., \& Miles, R. C. Acquisition of barpressing in rats following experience with responseindependent food. Animal Learning \& Behavior, 1977, 5, 236242.

Wheatley, K. L., Welker, R. L., \& Miles, R. C. Acquisition of barpressing in rats following experience with responseindependent food. Animal Learning \& Behavior, 1978, 6, 51. (Erratum)

(Received for publication November 6, 1981.) 